\title{
Gastric ulceration in dog: A review
}

J. D. Parrah, B. A. Moulvi, Mohsin Ali Gazi, D. M. Makhdoomi, H. Athar, Shahid Dar and A. Q. Mir

Faculty of Veterinary Sciences and Animal Husbandry

Sher-e-Kashmir University of Agricultural Science and Technology, Kashmir, India

Corresponding author: Mohsin Ali Gazi, email:mohsingazi9975@gmail.com

Received: 24-10-2012, Accepted: 20-11-2012, Published online: 01-05-2013

\begin{abstract}
How to cite this article:
Parrah J D, Moulvi BA, Gazi MA, Makhdoomi DM, Athar H, Dar S and Mir AQ (2013) Gastric ulceration in dog: A review, Vet World 6(7): 449-454, doi: 10.5455/vetworld.2013.449-454
\end{abstract}

\begin{abstract}
The common acid related diseases of the upper gastrointestinal tract could be considered as primarily due to the defect in barrier function either of the gastric mucosal or duodenal epithelium leading to the formation of gastric or duodenal ulcers. An attempt was made in this review to discuss the classification, pathophysiology, diagnosis and treatment of gastric ulcer in dogs. Early surgical advances in the management of peptic ulcers are emphasized that were then subsequently replaced by pharmacological treatment (histamine H2-receptor antagonists, proton pump inhibitors) and considered as the major strategy against the acid disorders.
\end{abstract}

Keywords: dog, gastrointestinal tract, stomach, ulcer

\section{Introduction}

In narrow sense, gastric ulcer is a defect in the mucosa that penetrates the muscularis mucosa [1]. But in real sense gastric ulceration and gastrodudonal ulceration describe a clinical finding, the cause of which is likely to be multifactorial and to differ from one case to another, and are anatomical circumscribed breaks in the surface of gastrointestinal mucosa. The ulcer of the stomach or the proximal duodenum is also called peptic ulcers, because these ulcers are bathed by acid pepsin [2].

Gastrodudonal ulcers can occur independently or as a complication of many systemic diseases or following administration of various drugs to treat many diseases, hence have paramount significance for any clinician to understand its etiological factors, pathophysiology for their effective treatment and early prophylaxis.

\section{Classification of gastric ulcers}

A classification of gastric ulcers is very important to know for the clinician as the treatment regimen varies widely for each class of gastric ulcer. The gastric ulcers are classified according to their depth in the gastrointestinal mucosa, anatomical location in the gastrointestinal area and the severity of the clinical presentation.

Gastrodudenal ulcers may be glandular mucosal ulceration, generalized gastritis, focal duodenal ulceration, duodenal erosions or duodenitis [3]. Depending upon the depth of the ulcer, gastric ulcers can be superficial or deep and range from simple epithelial erosion to full thickness bleeding or

This article is an open access article licensed under the terms of the Creative Commons Attribution License (http://creativecommons. org/licenses/by/2.0) which permits unrestricted use, distribution and reproduction in any medium, provided the work is properly cited. perforating ulcers. And on the basis of clinical presentation, ulcers may be acute or chronic [4].

\section{Incidence of gastric ulcerations}

Gastric ulcers are found both in young and adult animals, but higher percentage is found in mature animals. Likewise athletic animals do suffer more from gastric ulceration compared to the canine population as large. Endoscope studies have revealed gastric ulceration is $48.5 \%$ into canine athletes. Some incidence of gastric ulcers is also reported in foals- 25 to $50 \%$ [4].However, higher incidence of gastric ulcers $60 \%$ has been reported in mature horses. [4]. Gastroendoscopy has revealed gastric ulceration in horses as well as in animals with associated symptoms like poor appetite, poor body conditions or signs of abdominal discomfort [5]. However, the incidence of gastric ulceration in relation to the exciting cause also varies significantly from species to species. Unlike humans with renal failure in whom gastric ulcer predominates, gastric necrosis and ulceration appear to be uncommon in dogs with renal failure-3.6\% $[5,6]$.

\section{Etiology}

Gastric ulcer may be caused by various factors and these factors may range from inflammatory conditions of non steroidal and steroidal (glucoco-rticoid) antiinflammatory drugs for treatment of various diseases besides primary and secondary tumors of stomach, systemic disease and ingestion of poisonous and other harmful substances. Ulcers have been reported in dogs, rodents, horses and human secondary to administrations of a variety of non-steroidal anti-inflammatory drugs piroxicam [6] including, aspirin, ibuprofen [7], naproxen [8], endomethacine [9], ketrolac [10]. Steroidal anti inflammatory drugs are also incriminated as cause of gastric ulceration [11], for the treatment of other 
primary diseases like spinal insult like intervertebral disk disease [12], primary neoplastic condition of the stomach carcinoma, gastric intestinal lymphoma [13], gastrinoma and disseminated mast cell disease [14] are also responsible for gastric ulceration. Gastric ulcers have been noticed after the dogs have suffered from systemic diseases like hepatic, renal, Addison's disease; shock [15]. A range of exogenous toxins may cause gastric ulceration. Ingestion of household, cleaning chemical, lead and various plants may directly damage the gastric mucosa [16]. Three dogs following administration of phenol (total dose of $2430 \mathrm{mg}$ of phenol) experienced severe oral and gastric ulceration [17]. A lead salt mixture (Chloride Br, Sulfate, 1:1:2) when given orally to nine dogs at different dose rates ranging from $5-60 \mathrm{mg} / \mathrm{kg}$ body weight/day for 14-152 days induced gastric ulceration [18]. Gastric ulceration, as complication has been recorded following auto transplantation of the ovary to the portal vein drainage as a possible method of preventing obesity in ovariectomized bitches [19].

\section{Pathophysiology of gastric ulceration}

There are multiple pathophysiological mechanisms for the developments of ulcer in each of the disorders. However, the common underlying pathophysiological mechanism is stimulation of gastric acid secretion and inhibition of the gastric mucosal barrier properties. Acid secretary disorders are uncommon in companion animals but mucosal barrier disorders are fairly common.

In dogs, the multifactorial pathophysiological mechanism of gastric ulceration, thus stem from any processes, including physical damage to the gastric mucosa, impaired mucosal defense and chemical alteration to the mucosa and its repair process. Physical disruption of the mucosa that occurs normally with the passage of the particulate debris is rapidly corrected. After superficial insult, the damaged necrotic cells initially slough, become trapped in the superficial mucous layer and cover the lesion, tripping alkaline rich fluid leaking from exposed capillaries in and around the lesion. Superficial mucosal epithelial cells begin migrating immediately under this protective covering to reform the mucosal barrier within hours [20]. Ulcers develop from physical disruption only with sustained or significant trauma (Gastric foreign bodies, surgical implants) [21]. Gastric mucosa has a variety of defense mechanisms that protect and maintain epithelial integrity [22]. The gastric epithelial layer is in a continuous state of renewal, surface mucous cells are renewed in 3 days, whereas deeper neck mucous cells are renewed in 7 days [22]. Surface mucous cells, ingrate within 30-60 min to cover the small defects in the gastric epithelial lining of the basal lamina are intact. The mucosa receives $70 \%$ or more gastric blood flow to maintain protective and digestive functions [23]. Physiological levels of corticosteroids may be critical in maintain adequate blood flow during streaming. In addition, blood flow is supported by prostaglandin, which also increases mucous and bicarbonate production. Mucous has high viscosity, adhesive, and readily forms a film effectively coating the epithelium which can be assessed on radiograph [24]. This mucous layer is not digested by pepsin. It has selective permeability and traps alkaline fluid, creating a buffer zone against noxious or acid environment. Bicarbonate ion, produced by oxyntic cells and actively secreted into the luminal surface also acts as a chemical buffer.

Mucosal defense mechanism can be impaired by many means. Non-steroidal anti inflammatory drugs generally inhibit the cycloxygenase pathway (COX-1 and COX-2) through which prostaglandins are formed from Arachidonic Acid. Prostaglandins that are beneficial to the stomach are created through the COX1 pathway [25]. Without these beneficial PG's blood flow and gastric mucous and bicarbonate production are reduced. Corticosteroid increases gastric acid production and reduce PG's formation thereby promoting development or persistence of gastric ulcers [26]. Spinal insult may contribute to the development of diseases through altered gastric circulation and motility [26].

Shock reduces blood supply to the stomach and results in acidosis because of poor perfusion, both reduce delivery of bicarbonate ion to the surface cells. In animals, with renal failure, uraemia has been postulated to result in diffuse vascular injury to the mucosal lamina propria with subsequent epithelial cell damage from anoxia [27,28].

Chemical insult to the gastric mucosa comes from endogenous compounds ( $\mathrm{HCl}$, bile acids, and pancreatic enzymes) or exogenous $\mathrm{HCl}$. In Dogs, Helicobacter pylorus experimentally increases gastrin production by endocrine $\mathrm{G}$ cells, which increases production of the $\mathrm{HCl}$ by oxyntic cells. Whether Helicobacter pylori infection is clinically significant in dogs and cats is debatable. [28]. Histamine like gastrin is another primary messenger that stimulates $\mathrm{HCl}$ production by oxynitc cells through a cyclic adenosine monophosphate mediated secretary process. Animals with mast cell tumor and mastocytosis have increased circulating histamine concentration and are predisposed to gastric ulcer formation. Disease processes that decrease the removal of circulating gastrin or histamine such as renal or hepatic failure or that pathologically increase circulating gastrin levels [29], such as gastrinomas increase $\mathrm{HCl}$ production. Various positive feedback mechanisms may also increases gastric acid production. When the epithelial barrier is disrupted by any means, $\mathrm{HCl}$ is absorbed across the mucosa (acid back diffusion) and through stimulation of the intrinsic nervous system; it triggers release of more $\mathrm{HCl}$ and pepsin. $\mathrm{HCl}$ also directly stimulates tissue mast cells to release histamine, resulting in further $\mathrm{HCl}$ secretion. The duodenum plays a role in suppressing pathological gastrin and $\mathrm{HCl}$ release in normal animals. If gastric outflow is surgically altered e.g. (gastojejunostomy), 
ulcers are more likely to develop [30]. Duodenal contents (bile acids and pancreatic enzymes) may irritate gastric mucosa [31], although evidence suggests that these compounds without altered mucosal cellular metabolism do not induce ulceration. Exogenous toxins like lead may directly damage the gastric mucosa [32].

Systemic diseases like hepatic dysfunction may result in the decreased excretion of various xenobiotics and resulting in their producing side effects. Ketorolac is conjugated by the liver to an inactive metabolite and excreted by the kidney. Concurrent hepatic diseases may have prolonged its duration of activity thereby increasing the severity of side effects including gastro intestinal ulceration.

\section{Diagnosis}

The diagnosis of gastric ulceration is based on the following consideration;

I. Signalment and history: No breed, age or sex predilections are reported for gastric ulcer disease. History of the patient may indicate non-steroidal antiinflammatory drug (NSAID) therapy, ingestion of poisons and any other systemic disease like hepathopathy, tumor pregnancy gastric or secondary metastases.

II. Physical and clinical findings: Like the historical findings, physical findings at presentation range from non existent to severe. The animal might simply appear underweight or it could have a pale mucous membrane and tachycardia from severe anemia or shock. Pain on palpation may be apparent in the generalized if perforation with significant peritoneal contamination has occurred. The commonest clinical sign of gastric ulceration are vomiting, haemoptesis, melena, weight loss and anemia. Acute or chronic vomiting with or without hematemesis is the most common clinical sign associated with gastric ulcer or erosion formation not all animals with gastric ulcer vomit, however, and not all animals that vomit blood have gastric ulcers [32].

Other clinical signs observed include anorexia, abdominal pain, melena, anemia, edema (from hypoproteinemia related to elementary hemorrhage) and septicemia. (From perforation). Other signs may be related to the underlying cause (liver disease, neurologic disease). Perforation of the stomach or the duodenum may result in the sudden onset of severe weakness, severe abdominal pan, fever, shock abdominal distension and death caused by peritonitis [33]. Rarely animals with perforated gastric ulcer have only mild signs of abdominal discomfort. [34] Reported diarrhoea, progressive anorexia, 23-39\% body weight loss, vomition, depression and lethargy associated with primary gastrointestinal lymphosarcoma induced gastric ulceration in 3 male Shepard dogs and one Boxer dog. Almost similar signs but with addition of melena and pallor of the tongue has been reported in dogs associated with gastric ulceration secondary to the use of NSAIDS used for the treatment of orthopedic problem [35].

III. Laboratory finding: These are rarely specific for gastric ulcers. Results are evaluated for indicators of severity of clinical abnormality (anemia or septic abdominal fluid sample) and predictors of inciting cause e.g. (renal failure). Fecal occult blood is a difficult test to interpret, positive findings may be from bleeding in the stomach or small intestine of the patient is receiving a non-meat diet. Serum gastrin may be elevated in the patients with gastrinomas or decreased renal or hepatic clearance. Serum histamine levels may be increased if a mast cell tumor or mastocytosis is present.

Some diagnostic kits are also available for testing gastric juice. Gastro diagnose (Merck) is a preparation of pentagastrin, when injected IM @ 6 microgm $/ \mathrm{Kg}$ body weight. increases the gastric secretion (hyperacidity) in a dog suffering from gastric ulceration and perforation. The degree of endoscopically detected damage correlates well with sucrose permeability. Sucrose permeability decreases more rapidly than disappearance of the gastric ulcer. Sucrose permeability test is more sensitive to generalized mucosal damage than to discrete usual ulceration [36]. Neutrophilic leucocytosis was prominent laboratory finding in piroxicam associated gastric ulceration in dog. Dog suffering from gastric ulceration following phenol poisoning revealed hematological abnormalities including neutropenia with the presence of toxic neutrophils, thrombocytopenia and increased muscle enzyme [37].

IV. Radiography: Radiography (plain and contrast) are beneficial in determining potential cause of abdominal pain (gastric foreign bodies) but may be unrewarding in fetching evidence of gastric ulceration $[37,38]$ Could not find any gastrointestinal lesion in drug induced gastric ulceration, which were later confirmed by endoscopy. Focal, increased soft tissue density associated with traction of gastric wall may indicate perforation with an associated abscess. Generalized loss of serosal detail may indicate peritonitis secondary to perforation. For contrast radiography, barium sulphate produces a better study than iodine contrast agent, and requires multiple positions to identify lesions. Barium may adhere to mucosal defect or penetrate into urater. Small ulcers or larger defects filled with blood or debris may not be seen.

v. Ultrasonography: Ultrasonography is a useful noninvasive tool to detect the gastric ulceration in dogs. Ultrasonographic features of gastric ulcers includes local thickening of the gastric wall, possible loss of the 5- layer structure the presence of the wall defect or crater fluid accumulation in the stomach and diminished gastric motility. The localized gastric thickening usually varies from $9-16 \mathrm{~mm}$. The ulcer crater is often localized in the center of the thickened site and appears as a mucosal defect associated with persistent accumulation of small echoes, most likely representing micro bubbles. However, there is no 
definitive distinction between benign and malignant ulcers, and gas within the gastric lumen may interfere with imaging.

No biopsy of the center of the ulcer bed should be obtained as it can be easily perforated by the biopsy forceps and no blood should be inspired from the ulcer, as there are chances of renewed bleeding. Biopsy samples are collected from the edge of the ulcer to rule out neoplasia. Multiple biopsies of the same location are taken because superficial inflammation often accompanies neoplasia. Non lesioned biopsies are taken to identify diffuse gastritis. Perforation may be difficult to direct endoscopically because small lesion may seal over with omentum and perforation. Perforation is suspected if the stomach remains distended after the stomach is deflated or if abdominal radiographs reveal free gas in the abdomen after the procedure. If perforation is known to exist, endoscopy is contraindicated because examination increases contamination of the abdominal cavity with gastric contents.

\section{Treatment}

Medical therapy: Medical therapy is directed towardsa) Removing or attenuating is directed toward hepatic failure, hepatic bacter infection, non steroidal antiinflammatory drug or corticosteroid therapy.

b) Supporting ulcer healing by:

i) Maintaining mucosal perfusion

ii) Decreasing gastric acidity,

iii) Protecting ulcer

iv) Correcting secondary conditions (anaemia, dehydration, weight loss).Fluid therapy is important in dehydrated patients with gastric ulcers or maintains mucosal perfusion. Dehydration is quantities and corrected over an appropriate period. Acute life threatening haemorrhage from gastric ulcer is treated with blood transfusion, appropriate synthetic and natural colloid fluids where efforts to stop the haemorrhage are underway. If perfusion is imminent or confirmed, blood spectrum antibiotics or antibiotic combination are instituted [39].

Food is withheld at least initially to avoid stimulation of gastric acid and pepsin secretion. Subsequently dietary managements is similar to that recommended for acute gastritis. Patients, vomiting are given antiemetic as recommended for treatment of acute gastritis. Systemic acid reducing drugs fall into the categories of histamine $\left(\mathrm{H}_{2}\right)$ - blocking agents (Cimetidine, ranitidine, fomitidine) and proton pump inhibitors (omeprazole, lansoprazole, rabeprazole). $\mathrm{H}_{2}$. blocking agents reduce hydrochloric acid production that is stimulated at histamine receptors. Proton pump inhibitor decrease hydrochloric acid production from oxyntic cells by inhibiting the $\mathrm{H}^{+}, \mathrm{K}^{+}$-ATPase and work independently of specific receptors and thus may be more effective. Besides this, acid reducing drugs include those drugs that act on cellular metabolism to inhibit hydrogen on secretion (e.g. prostaglandins) [40]. A Cytoprotective drug such as sucralfate is important for protecting ulcerated tissue.

The $\mathbf{H}_{\mathbf{2}}$ antagonists: The $\mathrm{H}_{2}$ antagonists suppress $\mathrm{Hcl}$ secretion through competitive inhibition of the parietal cell histamine receptors. Gastroscopic examination has suggested that the degree of suppression of acid secretion required to heal lesion is greater than that required to produce relief from discomforts. $\mathrm{H}_{2}$ antagonist therapy should continue for 14-21 days; however in some cases healing will occur in 30-40 days.

Prostaglandin E analogs: Prostaglandin analogues (eg. misoprostol) may improve ulcer healing or prevent ulcer formation by increasing mucosal circulation, vascular permeability or mucosal cell turnover and migration. There drugs inhibit adenylate cyclase, reducing cyclic AMP production and thereby reducing the protein kinase activity essential to hydrogen ion generation. Misoprostol is a analogue of prostaglandin $\mathrm{E}_{1}$ that that is administered in doses of 0.5 to $2.3 \mu \mathrm{g} / \mathrm{lb}$ two or three times per day. It is the drug of choice for NSAID- induced ulceration and so more effective than sucralfate or $\mathrm{H}_{2}$ receptor antagonists in preventing NSAID -induced ulceration [40]. Some patients develop diarrhoea, which is usually self limiting. Prostaglandin $\mathrm{E}_{2}$ is not used in hypotensive animals because gastric damage may be increased.

Cimetidine: Cimetidine was the first $\mathrm{H}_{2}$ receptor antagonist used in dogs. It is available in injectable, liquid and tablet forms. Inhibition of histamine stimulated acid secretion peaks at $75 \%$ within 1.5 hours, and $50 \%$ inhibition of acid secretion lasts about 2 hours after an oral dose. Drug effects are gone after 5 hours. Thus cemetidine is administered 3-4 times daily at a dose of $2.5-5 \mathrm{mg} / \mathrm{lb}$ to suppress gastric acid secretion in dogs [41]. Even so, there is only mild to moderate inhibition of acid secretion over a 24 hours period. The fact that it works clinically for ulcer therapy suggests that even partial suppuration of gastric acid secretion is beneficial for the healing of most gastrodudenal ulcers.

Ranitidine: It is more potent and lasts longer than cemetidine. Inhibition of acid secretion peaks at $90 \%$ within 1.5 hours, and 50\% inhibition of acid secretion last about 4 hours after an oral dose. Ranitidine is usually effective clinically when administered at a $1 \mathrm{mg} / \mathrm{lb}$ twice a day. Ranitidine is available in injectable and tablet forms, and as syrup. Ranitidine can cause vomiting if rapidly administered I/V.

Fomitidine: It is more potent than either ranitidine or cemetidine. It is administered twice or once daily at 0.25 to $0.5 \mathrm{mg} / \mathrm{lb}$.

Nizatidine: This $\mathrm{H}_{2}$ receptor antagonist is like ranitidine and has prokinetic activity, hence may be preferable in patients with gastric ulcers co-existing with a motility disorder hypersensitive like reactors 
such as drug eruption or acute interstitial nephritis or poliomyelitis, hyperpyrexia, diarrhoea, granulocytopenia and central nervous system aberrations.

Protom pump blockers: Omeprazole: it is a substituted benzimidazole, blocks hydrogen ion secretion in the parietal cell by inhibiting $\mathrm{H}^{+}, \mathrm{K}^{+}$- ATPase located on the apical membrane. It is a weak base, accumulates in the acid compartments of the parietal cell, hence administered once daily at dose of 0.33 to $1 \mathrm{mg} / \mathrm{lb}$. Omeprazole is indicated for disease states that are not responsive to $\mathrm{H}_{2}$ receptor antagonist therapy, such as non respectable gastrinoma and systemic mast cell disease.

Aspirin: Administration of aspirin twice daily reduces periods of fecal blood volume [42].

Lansoprazole: it does not differ significantly from omeprazole in potency or duration of action.

Cytoprotective drugs: Cytoprotective drugs such as sucralfate protect healthy and denuded mucosa from further harm and promote gastric mucosal epithelialization [43].

Sucralfate a sulfated polysaccharide a non absorbable aluminum salt of sucrose octasulfate, is used as an adjunct to $\mathrm{H}_{2}$ antagonist therapy in treating gastric ulcers rather than using sucralfate alone because once clinical signs of ulcers are apparent, the severity of ulceration will warrant aggressive suppression of acute secretion as well as enhancement of mucosal protection because of an evidence that sucralfate adhere to gastric mucosa in an acidic medium [44]. It is advisable to administer sucralfate one to two hours before administration of $\mathrm{H}_{2}$ antagonist, but it also works adequately in a near neutral $\mathrm{Ph}$ [45,46], as might occur after $\mathrm{H}_{2}$ receptors antagonists therapy. Besides absorption of $\mathrm{H}_{2}$ receptor antagonists may be decreased 10 to $30 \%$ by sucralfate, hence sucralfate is given 30 to 60 minutes after administration of $\mathrm{H}_{2}$ receptors antagonists usually at a dose rate of $0.5-1 \mathrm{gm}$ two or four times daily orally. Because absorption is minimal, it has almost systemic effects and long term uses may lead to constipation. Proposal mechanism of sucralfate effects include augmentation of the mucus bicarbonate barrier, mucosal hydrophobicity, mucosal blood flow and cell vascularity, local production of prostaglandins, endogenous mediation of tissue injury and repair, cell binding and neutralization of hydrogen ion and pepsin blocking activity [47].

Other drugs: Exogenous administration of phospholipids may be useful in preventing gastric ulceration. Electron microscopy revealed the existence of surfactant as abundant osmiophilic phospholipids material within the canine gastric and duodenal mucosa [48].

Oral antacids like aluminium hydroxide, Magnesium Hydroxide are impractical for treatment of the gastric ulcers or erosions in the dogs. As there are to be administered at least 6 times per day in doses sufficient to titrate gastric acid. Cisapride may be helpful if the ulcer patient has concurrent motility problems resulting in the delayed gastric emptying [49].

Surgical interventions: Gastric surgery is less commonly performed to treat the gastric ulceration of erosion [50]. Surgical intervention is resorted to as the treatment of gastric ulceration when perforation is suspected or if severe bleeding is discovered. Serial evaluation of the haematocrit and cardiovascular assessment are necessary to determine whether blood loss is sufficient to warrant surgery. Surgery i9s also indicated if the patient has not responded to appropriate medical therapy that has been administered at least for 5-7 days.

Lesions are resected during exploratory laparotomy. Sometimes it is difficult to locate mucosal lesion when examining the serosal surface [50]. A thickening gastric wall may be detected resulting from inflammatory infiltrate around the lesion so that if multiple ulcers are present they can all be located.

\section{References}

1. Stanton, M. E, and Bright, R. M. (1989) Gastrodudenal ulceration in dogs. A retrospective study of cases and literature review. J.Vet. Intern. Med. 3:238-244.

2. Schaer, M. (2003) Peptic ulcer: In: Clinical Medicine of the dog and cat. Manson publishing Ltd. 73Colringham Road London, UK.

3. Murray (1991) Diagnosis and treating gastric ulcer in foals and horses. Vety. Medicine. 8: 820-827.

4. Bao, Y.(2010) History of peptic ulcer disease and pancreatic cancer risk in men. Gastroenterology 138 (2):541-549.

5. Peters, R. M., Goldsrein, R. E., Erb, H. N. and Njaa, B. L. (2005) Histopathologic features of canine uremic gastropathy: A retrospective study. J Vety Internal Medicine 19 (3) 315-320.

6. Lanza, F. L., Chan, F. K. and Quigley, E. M. (2009) Practice Parameters Committee of the American College of Gastroenterology. Guidelines for prevention of NSAIDrelated ulcer complications. Am J Gastroenterol. 104 (3): 728-738.

7. Godshalk, C. P., Roush, J. K., Fingland, R. B., Sujjena, D. and Vorhies, M. W. (1992) Gastric perforation associated with administration of ibuprofen in a dog. J. Am Vet Medical Assoc. 201:1734.

8. Malfertheiner P, Chan, F. K. L. and McColl, K. E. L. (2009) Peptic ulcer disease Lancet:;374(9699):1449-1461.

9. Spee LA.(2010) Association between Helicobacter pylori and gastrointestinal symptoms in children. Pediatrics. 125 (3):651-669.

10. Mathew, K. A., Paley, D. M., Foster, R. A., Valliant, A. E. and Young, S.S.(1996) A comparision of ketrolac with flunixin, Butorphenon and oxymorphone in controlling post operative pain in dogs. Canadian Vety. Journal. 37(9): 557-567.

11. Grainek, I. M., Barkun, A. N. and Bardou, M. (2008) Management of acute bleeding from a peptic ulcer. $N$ Engl J Med.359 (9): 928-937.

12. Neiger, R., Gaschen, F. and Jaggy, A. (2000). Gastric mucosal lesions in dogs with acute intervertebral disc disease: characterization \& effects of omperazole or misoprostol, J. internal Med. $14: 33$.

13. Grooters, A. M., Sherding, R. G. and Johnson, S. E. (1994) Endoscopy case of the month: Chronic vomiting and weight loss in a dog. Vety Medicine 89: 3, 196-199.

14. Giannini, E. G., Bilardi, C., Dulbecco, P., Mamone, M., 
Santi, M. L., Testa, R., Mansi, C. and Savarino, V. (2006) Can Helicobacter pylori eradication regimens be shortened in clinical practice. An open-label, randomized, pilot study of 4 and 7-day triple therapy with rabeprazole, high-dose levofloxacin, a tinidazole. J Clin Gastroenterol. 40(6):515-520.

15. Hall, J. A. (2000) Disease of the stomach. In Ettinger S, J. \& Feldman, E.C (eds): Textbook of Veterinary internal medicine. WB Saunders, Philadelphia, Pp. 1156.

16. Sass, B. (1970) Perforating gastric ulcer associated with lead poisoning in a dog. J Am Vet Med Assoc 157: 76.

17. Gieger, T. L., Correa, S. S., Taboada, J., Grooters, A. M and Johnson, A. J. (2000) Phenolo poisioning in three dogs. J. American Animal Hospital Association. 36(4): 317-321.

18. Hamir, A. N. and Sullivan, N.D.(1983). Extrameural lesions in experimental lead toxicosis of dogs. J. Small Animal Practice. 24(7): 437-444.

19. Davis, M. S., Willard, M. D., Nelson, S. L., Mandsagar, R. E., Mekiernan, B. S., Mansett, J. K. and Lehenbaur, T. W. (2003) Prevalance of gastric lesions in racing Alaskan sled dogs. Journal of Veterinary Internal Medicine. 17(3):311-314.

20. Lacy, E. R. (1987) Gastric mucosal defenses after superficial injury, Clinic Internal Medicine 10; 189.

21. Alder, P. (1979) Penetrating gastric ulceration in a dog. J. Am Vet. Med.Association 175:710.

22. Strombeck, D. R. and Guilford, W. G (1990): Small animal gastroenterology, 2nd ed. Saunders Publishing Co.

23. Barkun, A. and Leontiadis, G. (2010) Systematic review of the symptom burden, quality of life impairment and costs associated with peptic ulcer disease. Am. J Med.;123(4):358366.

24. Duan S Y, Zhang D T, Lin Q C and Wu Y H (2006).Clinical value of $\mathrm{CT}$ three-dimensional imaging in diagnosing gastrointestinal tract diseases. World J Gastroenterol. 12(18): 2945-2948.

25. National Institutes of Health Press Release (2009) NIH Study Finds Low Short-term Risks After Bariatric Surgery for Extreme Obesity.

26. Rohrer, C. R., Hill, R. C. and Fischer, A. (1999) Gastric haemorrhage in dogs given high doses of methyl prednisolone sodium succinate Am. J. Res 60:977.

27. Chan F K. (2010) Celecoxib versus omeprazle and diclofenac in patients with osteoarthritis and rheumatoid arthritis (CONDOR): a randomized trial. Lancet. 376 (9736): 173-179.

28. McColl K. E. L. (2010) Helicobacter pylori infection. NEJM.362(17):1597-1604.

29. Wu CY, Kuo KN, Wu MS, Chen YJ, Wang CB and Lin JT. (2009) Early Helicobacter pylori eradication decreases risk of gastric cancer in patients with peptic ulcer disease. Gastroenterology 137(5):1641-1648.

30. Feinstein LB, Holman RC, Christensen KLY, Steiner CA and Swerdlow DL.(2010) Trends in hospitalizations for peptic ulcer disease, United States, Emerg Infect Dis.; 16(9):14101418.

31. Thompson W. G. (2008) Understanding the Irritable Gut. McLean, VA: Degnon Associates. Hindawi Publishing Co.

32. Otto, C.M., Dodds, W.J. and Greene, C.E.(1991). Factor XII and partial prekalli krein deficiencies in a dog with recurrent gastrointestinal hemorrhage. 198: 129-131.

33. Banerjee, S., Cash, B. D., Dominitz, J. A., Baron, T. H., Anderson, M. A., Ben-Menachem, T., Fisher, L., Fukami, N. and Harrison, M. (2010) ASGE Standards of Practice Committee. The role of endoscopy in the management of patients with peptic ulcer disease. Gastrointest Endosc. 71(4):663-668.

34. Cortese, M. M., Tate, J. E., Simonsen, L., Edelman, L. and Parashar, U. D. (2010) Reduction in gastroenteritis in United States children and correlation with early rotavirus vaccine uptake from national medical claims databases. Pediatr Infect Dis J. 29(6):489-94.

35. Wallace, M.S.,Zaine, D.A and Garvey, H.S(1990). Gastric ulceration in the dog secondary to the use of non steroidal anti inflammatory drugs. J.Am Anim Hosp Assoc. 26:467.

36. Meddings, J.B., Kirk,D. and Olson, M.E.(1995). Noninvesive detection of nonsteroidal anti-inflammatory drug induced gastropathy in dogs. Am. J. Vet. Research. 56(8): 977-981.

37. Talbert, A., Thuo, N., Karisa, J., Chesaro, C., Ohuma, E., Ignas, J., James, A., Christopher, T., Sarah, A. (2012) Diarrhoea complicating severe acute malnutrition in kenyan children: a prospective descriptive study of risk factors and outcome. PLoS One.;7(6):38321.

38. Guarino, A., Albano, F., Ashkenazi, S., Dominique, G., Hans, H., Raanan, S. and Hania, S. (2008) European Society for Paediatric Gastroenterology, Hepatology, and Nutrition/ European Society for Paediatric Infectious Diseases evidence-based guidelines for the management of acute gastroenteritis in children in Europe: executive summary. $J$ Pediatr Gastroenterol Nutr. 46(5):619-21.

39. Guandalini, S. (2011) Probiotics for prevention and treatment of diarrhea. JClin Gastroenterol, 45 Suppl:S149-53.

40. Lanza, F. L., Chan, F. K. and Quigley, E. M. (2009) Guidelines for prevention of NSAID-related ulcer complications. American Journal of Gastro-enterology, 104(3): 728-738.

41. Ephgrave, K.S and Horton, J.W (1987) comparison of approaches to stress ulcers prophylaxsis in hemorrhagic shock J. Surg Res . 43:52.

42. Jenkins C.C, De Novo R.C, Patton C.S Bright, R.M and Rohrbach, B.W. (1991) Comparison of effects of cimetidine \& omperazole on mechanically created gastric ulceration \& on aspirin induced gastritis in dogs. Am. J.Vet .Res. 52:658661.

43. Kuwayama, H., Matsuo, Y. and Eastwood, G. L. (1991). Effects of Sucrulfate, lansoprazole \& cimetidine on the delayed healing by hydrocortisone sodium phosphate of chronic gastric ulcers in the rat. Am. J. Med, 91: 151.

44. Danesh, J. Z, Duncan, A and Russel, R. I (1988) Effect of intragastric $\mathrm{pH}$ on mucosal protective action of sucrulfate . Gut 29:1379-1385.

45. Rees, W. D. (1991), Mechanism of gastroduodenal protection by sucrulfate Am. J. Med 91-585.

46. Borella, L. E., Seethaler, K. and Lippmann, W. (1979) Sucrulfate, Antipeptic, antiulcer activities \& antagonism of gastric emptying, Avzeimmittelforscheing 29: 793.

47. Wada, K., Kamisaki, Y., Kitano, M., Kishimoto, Y., Nakamoto, K. and Itoh, T. (1997) Effects of sucrulfate an acute gastric mucosal injury \& gastric ulcer induced by ischemia reperfusion in rats. Pharmacoloy 54: 57.

48. Ethell, M. T, Hodson, D. R and Hills, B. A (1999) Ultrastructure of the hydrophobic gastric surfactant in the dog. Australian-Veterinary Journal. TT (u) : 240-244.

49. Washabau, R. J and Halt, J. A (1995) Cisapride Journal of American Veterinary Medical Association, 207:1285-1288.

50. Fossum, T. W and Hedlund, C. S. (2003) Gastric and intestinal surgery. Veterinary Clinics of North America, Small Animal Practice. 33(5): 1117-1145. 